\title{
Inversion of ocean-bottom seismometer (OBS) waveforms for oceanic crust structure: a synthetic study
}

\author{
Xueyan Li $\cdot$ Yanbin Wang $\cdot$ Yongshun John Chen
}

Received: 11 May 2016/ Accepted: 6 July 2016/Published online: 19 August 2016

(C) The Author(s) 2016. This article is published with open access at Springerlink.com

\begin{abstract}
The waveform inversion method is appliedusing synthetic ocean-bottom seismometer (OBS) data-to study oceanic crust structure. A niching genetic algorithm (NGA) is used to implement the inversion for the thickness and P-wave velocity of each layer, and to update the model by minimizing the objective function, which consists of the misfit and cross-correlation of observed and synthetic waveforms. The influence of specific NGA method parameters is discussed, and suitable values are presented. The NGA method works well for various observation systems, such as those with irregular and sparse distribution of receivers as well as single receiver systems. A strategy is proposed to accelerate the convergence rate by a factor of five with no increase in computational complexity; this is achieved using a first inversion with several generations to impose a restriction on the preset range of each parameter and then conducting a second inversion with the new range. Despite the successes of this method, its usage is limited. A shallow water layer is not favored because the direct wave in water will suppress the useful reflection signals from the crust. A more precise calculation of the air-gun source signal should be considered in order to better simulate waveforms generated in realistic situations; further studies are required to investigate this issue.
\end{abstract}

Keywords Waveform inversion - OBS - Oceanic crustal structure $\cdot$ Niching genetic algorithm

Submitted to: Earthquake Science.

X. Li · Y. Wang $(\bowtie) \cdot$ Y. J. Chen

Department of Geophysics, School of Earth and Space Sciences, Peking University, Beijing 100871, China

e-mail: ybwang@pku.edu.cn

\section{Introduction}

Seismic waveform inversion is a technique to extract quantitative information on subsurface structure by fitting the synthetic seismograms with that of observation. Through comparison with a travel-time-based method, fullwaveform inversion can improve the resolution of the model as it uses both the amplitude and phase information of various seismic phases contained in seismograms. As the wave equation is directly solved in this method, higherorder effects such as diffractions and multiple scattering are accounted for automatically (Pratt 1999). Many studies on the regional continental crust and upper-mantle structure have been carried out using waveform inversion (Das and Nolet 1998; Sherrington et al. 2004; Shibutani et al. 1996; Zheng et al. 2006; Zhu et al. 2006). Full-waveform inversion is a strong nonlinear optimization process. For gradient-based local searching methods, the final model is strongly related to the initial model and may be trapped into local minima. It is computationally time-consuming to perform large-scale forward modeling of seismic wave field propagation (Virieux and Operto 2009).

For regions where subsurface structure can be approximated by a layered model, global optimization methods, such as genetic algorithm and simulated annealing, can be applied to full-waveform inversion to improve its efficiency and convergence (Sen and Stoffa 2013). A layered 1D velocity structure is the most simplified, but fundamental, approximation of the Earth. It plays a significant role in accurate seismic location, calculation of Green's function, and can serve as the initial model for inversion of fine $2 \mathrm{D}$ or $3 \mathrm{D}$ velocity structure. A more accurate layered crust model could also contribute to improved study of the deeper Earth structure. Recently, waveform inversion has 
been conducted at several regions to extract layered continental crustal and upper-mantle structure using the data recorded from local seismic networks with global optimization methods (Abdelwahed and Zhao 2014; Chang and Baag 2006; Li and Lei 2014a, b; Li et al. 2007, 2012).

The oceanic crustal and upper-mantle structure is less well investigated than continental cases because of lack of seismic observation data. Researchers attempted to invert waveform data obtained from ocean reflection experiment for elastic parameters of oceanic crust (Igel et al. 1996; Mendes et al. 1990) and crust and upper-mantle velocity structure from surface waves (Cara and Lévêque 1987; Debayle and Lévêque 1997). In recent years, ocean-bottom seismometer (OBS) techniques have provided increasing amount of seismic data to study the oceanic crust of localized areas, such as north-eastern Japan (Takahashi et al. 2004), Lucky Strike segment (Seher et al. 2010), Southwest Indian Ridge (Li et al. 2015) and north-eastern South China Sea (Zhao et al. 2010). Full-waveform inversion has been applied to OBS data to improve the resolution of oceanic crust structure (Jian et al. 2014; Operto et al. 2006; Borisov and Singh 2015).

This paper attempts to extend a full-waveform inversion scheme used for continental crust and upper-mantle structure studies to the investigation of the oceanic crust using OBS data. Synthetic OBS data generated from an air-gun source in water is used. One significant difference between land and OBS observation is the presence of the water layer, which produces multiples and strong direct waves that cannot be used in waveform inversion. The validity and efficiency of OBS data methods are studied with the use of synthetic numerical models. Considering a limited number and sparse distribution of OBS stations, compared with the land seismic network, an attempt is made to perform inversion for a layered oceanic crust model. The parameters of interest include thickness and P-wave velocity of the sedimentary layer and crust. A niching genetic algorithm (NGA) is employed to perform the global optimization for the waveform inversion. The influence and performance under different observation systems of some key parameters in the NGA method are investigated, and a strategy is proposed to accelerate the convergence rate without increasing the computational complexity. This strategy is verified through comparative tests.

\section{Waveform inversion method}

Waveform inversion is a highly nonlinear problem. There are many traditional methods that can be used to determine seismic velocity structure through the use of waveform inversion, such as the conjugate gradient method, the grid search method, genetic algorithms (GA), and simulated annealing. Their common point is that they can only give one minimum of the objective function as the final model, and it is possible that the solution may converge to a local minimum if the initial model is quite far away from the real model (Maurice et al. 2003). However, NGA can search different minima by simulating the evolutionary processes in biology, such as crossover, mutation, selection, and competition (Mahfoud 1995). Hence, NGA is quite suitable for a multimodal optimization problem in geophysics. Koper et al. (1999) developed the NGA and applied it in a teleseismic waveform inversion for the source parameters of the $M_{\mathrm{w}} 7.2$ Kuril Islands earthquake in 1996. Maurice et al. (2003) inferred the crustal and upper-mantle structure under southernmost South America through the use of NGA. Lawrence and Shearer (2006) gave a constrained seismic velocity and density for the mantle transition zone, and $\mathrm{Li}$ et al. (2012) inferred the 1D crustal structure under south-eastern Gansu, China, by applying NGA to regional waveform inversion.

Several researches have investigated the effects of different objective functions and parameters in NGA, such as the number of models in each subpopulation, and the critical separation radius (Koper et al. 1999; Li and Lei 2014a). In this paper, further discussion of NGA implementation is presented based on these previous studies, and an attempt is made to illustrate some other factors that could influence the resultant final model.

The NGA works as follows: first of all, initial models are created and then divided into $n$ subpopulations, or demes. A deme represents a group of models that are close to each other in the whole model space, and there is a distance between different demes. We set each deme to contain $m$ models. Traditional genetic algorithm approach is carried out in each deme to work out the second deme, but in NGA the similarity of each member of this deme is calculated with respect to the best model from the former ones. Similarity is an important parameter. The simplest approach is to define the distance, $D$, of two models, $\mathbf{x}$ and $\mathbf{y}$, as the arithmetic average of the normalized separation of the model parameters (Koper et al. 1999), as shown in Eq. (1),

$D(x, y)=\frac{1}{m} \sum_{i=1}^{m} \frac{\left|x_{i}-y_{i}\right|}{b_{i}-a_{i}}$,

where $m$ represents the number of parameters we need to search, $x_{i}$ and $y_{i}$ are the $i$ th parameters of models $\mathbf{x}$ and $\mathbf{y}$, and $b_{i}$ and $a_{i}$ are the upper and lower bounds of the $i$ th parameters. The similarity varies from 0 , for two identical models, to 1 for two models at opposite ends of the search boundary. If one's similarity exceeds a specified criterion (called $R_{\mathrm{c}}$ ), then that model is given a high penalty and is 
eliminated in the next generation. This process continues until it reaches the final generation.

\section{NGA implementation}

\subsection{Model parameterization}

The waveform inversion assumes a layered, laterally homogeneous model and seeks to invert for crustal and upper-mantle thickness and P-wave velocity. The S-wave velocity for each layer is derived from the relationship $v_{\mathrm{S}}=k v_{\mathrm{P}}$, where $k$ can be determined by the Poisson ratio of each layer. For the crustal layer, $k$ is set to 0.577 , which means that the Poisson ratio is equal to 0.25 for this case. For the sediment layer, $k$ is equal to 0.489 . The synthetic model is designed by considering the oceanic crust model given by Rao et al. (2012) and Arnulf et al. (2014). The model parameters are listed in Table 1.

\subsection{Objective function and synthetic seismograms}

The primary component of the objective function is the average value of root-mean-square residual between the synthetic and observed seismograms and their cross-correlation in the time domain. This is shown in Eq. (2):

$$
\begin{aligned}
\operatorname{Cost}= & \frac{1}{2} \times \frac{\sqrt{\sum_{i} \sum_{j}\left(O_{i j}-S_{i j}\right)^{2}}}{N_{w} \times \sqrt{\sum_{i} \sum_{j} O_{i j}^{2}}} \\
& +\frac{1}{2} \times\left[1-\frac{1}{N_{w}} \times \sum_{i} \frac{\max \left(O_{i} \times S_{i}\right)}{\sqrt{O_{i} \times O_{i}} \sqrt{S_{i} \times S_{i}}}\right],
\end{aligned}
$$

where $O(t) \times S(t)=\int O(\tau) S(t-\tau) \mathrm{d} \tau$, and $N_{w}$ is the number of waveforms used. The first term of this formula is the root-mean-square error, $O_{i j}$ and $S_{i j}$ are the amplitudes of the observed and synthetic seismograms of the $i$ th component at the jth sampling point. The second term contains the cross-correlation of the synthetic and observed waveform, which shows their similarity. $O_{i}$ and $S_{i}$ are the $i$ th waveform of the observed and synthetic seismograms. This objective function takes into account both the amplitude

Table 1 Theoretical model used in this study

\begin{tabular}{lllll}
\hline Layer & Thickness $(\mathrm{km})$ & $v_{\mathrm{P}}(\mathrm{km} / \mathrm{s})$ & $v_{\mathrm{s}}(\mathrm{km} / \mathrm{s})$ & $\rho\left(\mathrm{g} / \mathrm{cm}^{3}\right)$ \\
\hline Water & 3.2 & 1.5 & 0 & 1.05 \\
Sediment & 1.8 & 2.3 & 1.125 & 2.00 \\
1 & 3.0 & 5.5 & 3.176 & 2.55 \\
2 & 2.5 & 6.7 & 3.868 & 2.85 \\
3 & 4.0 & 7.1 & 4.099 & 3.10 \\
Upper mantle & & 8.1 & 4.677 & 3.25 \\
\hline
\end{tabular}

and phase information of each seismic phase ( $\mathrm{Li}$ et al. 2012).

A seismic wave field generated from an air-gun source in the water is studied. Synthetic waveforms are calculated using a reflectivity method (Fuchs and Müller 1971). In comparison with land-based observation, a major difference to OBS data is the existence of the water layer, which produces multiples in the water and strong direct waves that cannot be used in the inversion for subsurface structure. In the forward modeling, the water multiples are removed by omitting them from the calculation since they are useless for the crustal structure, though they are of a high amplitude. The direct wave propagating in the water cannot be ignored, and poses the biggest challenge to this study. The very strong direct wave and relatively weak series of reflection waves from the crust are visible in Fig. 1. With the increase of the offset, the direct wave tends to become mixed up with the first reflection phase. This prevents the study of a rather large area, restricting the study region in which the direct wave and reflection wave are separated. The useful reflection signals for inversion are selected, and the direct wave is ignored.
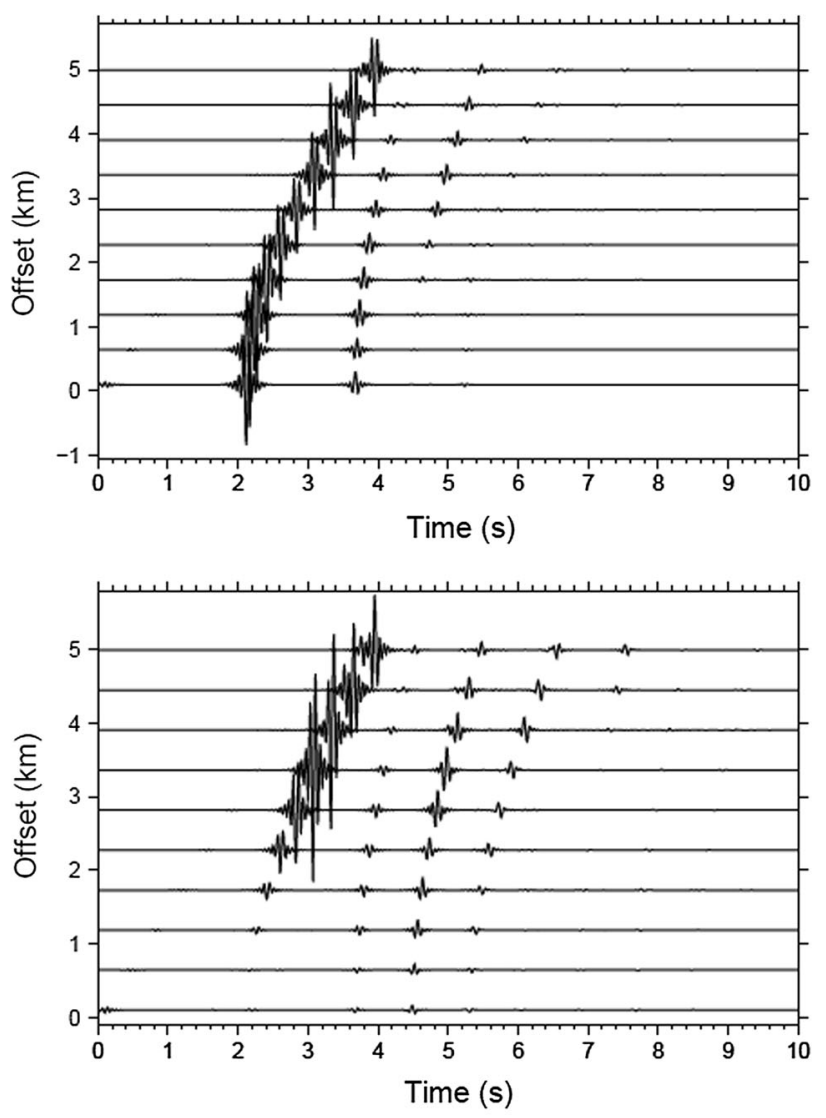

Fig. 1 Synthetic seismograms calculated by the reflectivity method. The upper and lower panels represent the vertical component and the radial component, respectively 
The seismic source is an explosive type, and a Ricker wavelet is used to imitate the air-gun signal. The source is located at a depth of $20 \mathrm{~m}$ in the water layer. Considering that the real air-gun signal contains more high-frequency components, a Butterworth band-pass filter is applied to the source with corner frequencies of 5 and $15 \mathrm{~Hz}$, and a central frequency of $10 \mathrm{~Hz}$.

The first phase with a large amplitude shown in Fig. 1 is the direct wave, which adds a large noise signal to the reflected waves. Since they are not overlapped, a time window can be used to pick up the subsequent reflections for waveform inversion.

\section{Numerical test of parameters in NGA method}

\subsection{General test}

As shown in Table 1, a total of five P-wave velocities and four thicknesses of layers are searched. The searching ranges are within $\pm 0.5 \mathrm{~km} / \mathrm{s}$ for $v_{\mathrm{P}}$ and $\pm 30 \%$ for the thickness around the preset values described in Table 1. In the first test, ten receivers are set, in line, at the surface of the sediment layer, each between 100 meters and $5 \mathrm{~km}$ in horizontal distance apart from the source, as shown in Fig. 2. The NGA inversion is calculated for 500 generations with ten demes, with each deme containing ten models. Seven different NGA runs are performed, using different random model generators (by changing the random number value in the NGA). The average of seven results is taken, with the minimum value of the objective function in each run being used for the final model, with their standard deviation as the error. The probabilities of

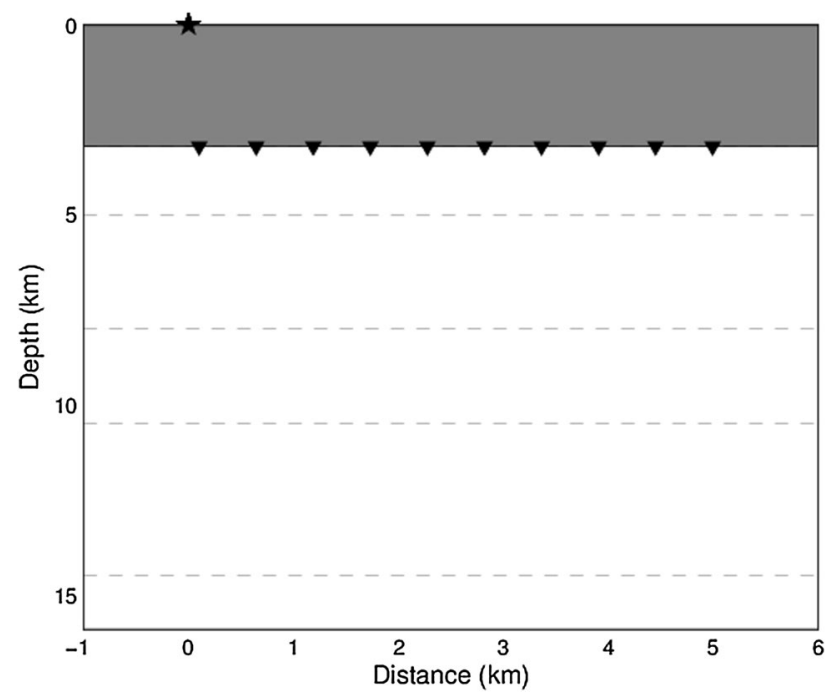

Fig. 2 Descriptive sketch for the distribution of air-gun source $(\star)$ and OBS receivers (triangles) crossover and mutation are set to 0.90 and 0.10 , respectively.

The results shown in Table 2 and Fig. 3 show the comparison of the inversion result with the true model. Figure 4 shows the cost-generation curve. It is clear that the convergence rate slows down gradually, and that the change becomes negligible after hundreds of generations. It is evident from Fig. 5 that the waveform is a good fit.

\subsection{Number of models in each deme}

The number of models $\left(N_{\mathrm{m}}\right)$ in each deme has a great effect on the result of the NGA inversion. If $N_{\mathrm{m}}$ is too small, then the rate of convergence will be low if there is poor diversity in each subpopulation. This could easily be solved by increasing the number of models, which would also lead to more computing time. So there is a trade-off between improving the convergence rate and cutting down the computing cost. A test is performed with $N_{\mathrm{m}}$ equal to 6,8 , 10, 12, and 16. It is evident from Fig. 6 that the results of the test with the smallest value of $N_{\mathrm{m}}$ have the lowest quality, and that quality improves as $N_{\mathrm{m}}$ increases. It was found that once $N_{\mathrm{m}}$ has reached a value greater than 10 , then there is no further apparent change in the cost value. For an appropriate balance of accuracy and time requirement, $N_{\mathrm{m}}$ equal to 10 was selected.

\subsection{Critical distance $R_{\mathrm{c}}$}

It is always the hope that the inversion method can search the whole solution space and avoid converging on the local minima as much as possible. In NGA, this is carried out by choosing a suitable $R_{\mathrm{c}}$ value, which controls how different subpopulations migrate into different niches of the solution space. If $R_{\mathrm{c}}$ equals 0 , then all demes will inhabit global minimum as no artificial distinction exists between each deme, like performing several GA at the same time. However, if $R_{\mathrm{c}}$ is too large, then only the best model evolves with time, while the others are artificially ruled out and become "frustrate". According to Koper et al. (1999), the cost value of a model that is "frustrate" always remains high and shows little improvement over time, being reinitialized randomly after every generation. This is undesirable behavior, because competition and selection between useful demes is required in order to efficiently search for the optimum model.

Four different $R_{\mathrm{c}}$ values are selected for this test: 0.01 , $0.1,0.2$, and 0.3 . Values greater than 0.3 resulted in poor performance in pretest and are not discussed. It is evident that the cost value is not so favorable when $R_{\mathrm{c}}$ is equal to 0.3 , and from Fig. 7 there is no obvious distinction between the other tests. It is only by examining the results of the 200th generation that some subpopulations are separated when $R_{\mathrm{c}}$ equals 0.1 or 0.2 . With $R_{\mathrm{c}}$ equal to 0.01 , most 
Table 2 Comparison of results from waveform inversion with the theoretical model, for the general test described in Sect. 4.1

\begin{tabular}{llll}
\hline $\begin{array}{l}\text { Theoretical model } \\
\text { thickness } H(\mathrm{~km})\end{array}$ & $\begin{array}{l}\text { Inversion result } \\
\text { thickness } H \pm \sigma(\mathrm{km})\end{array}$ & $\begin{array}{l}\text { Theoretical model P-wave } \\
\text { velocity } v_{\mathrm{P}}(\mathrm{km} / \mathrm{s})\end{array}$ & $\begin{array}{l}\text { Inversion result P-wave } \\
\text { velocity } v_{\mathrm{P}} \pm \sigma(\mathrm{km} / \mathrm{s})\end{array}$ \\
\hline 1.8 & $1.798 \pm 0.002$ & 2.3 & $2.298 \pm 0.002$ \\
3.0 & $3.003 \pm 0.010$ & 5.5 & $5.504 \pm 0.016$ \\
2.5 & $2.515 \pm 0.258$ & 6.7 & $6.539 \pm 0.199$ \\
4.0 & $3.702 \pm 0.521$ & 7.1 & $6.870 \pm 0.230$ \\
& & 8.1 & $7.668 \pm 0.098$ \\
\hline
\end{tabular}

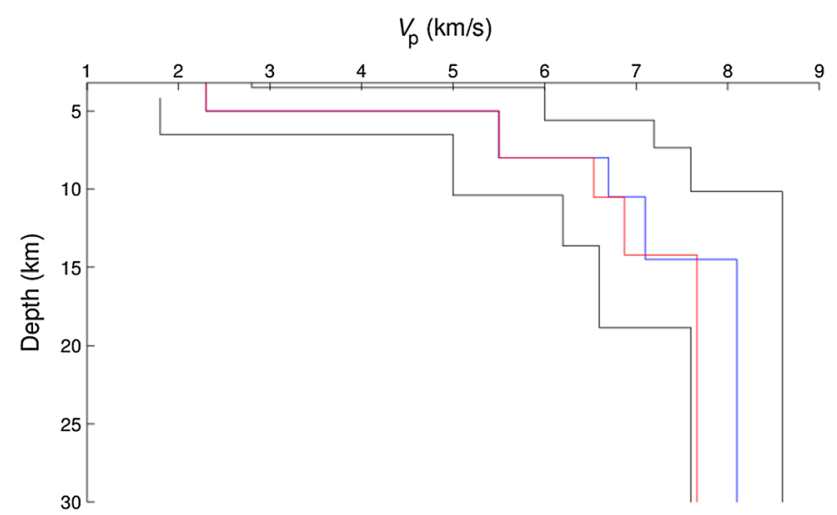

Fig. 3 Comparison of the average model (red line) from seven NGA inversions with the true models (blue line). The preset ranges for velocity and depth, over which the model parameters are allowed to change in the inversion, are shown by black lines

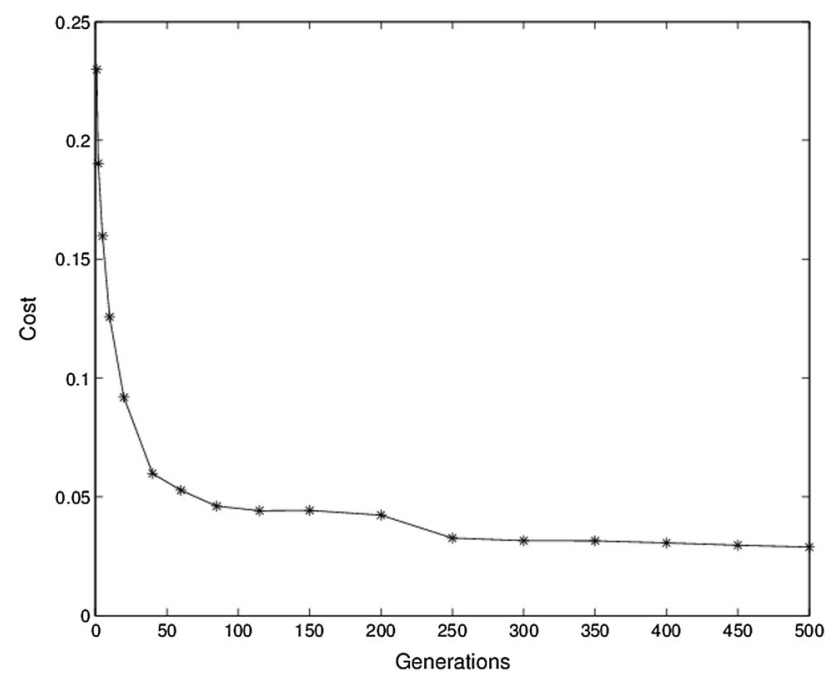

Fig. 4 Cost versus generations. Under the general test in which the total number of generations is $500, R_{\mathrm{c}}$ is 0.1 , and the number of models is 10

subpopulations converge to the global minimum. Considering the competition between subpopulations, it is desirable to set $R_{\mathrm{c}}$ between 0.1 and 0.2 in order to make our NGA different from the traditional GA, while at the same time ensuring that none, or very few, subpopulations
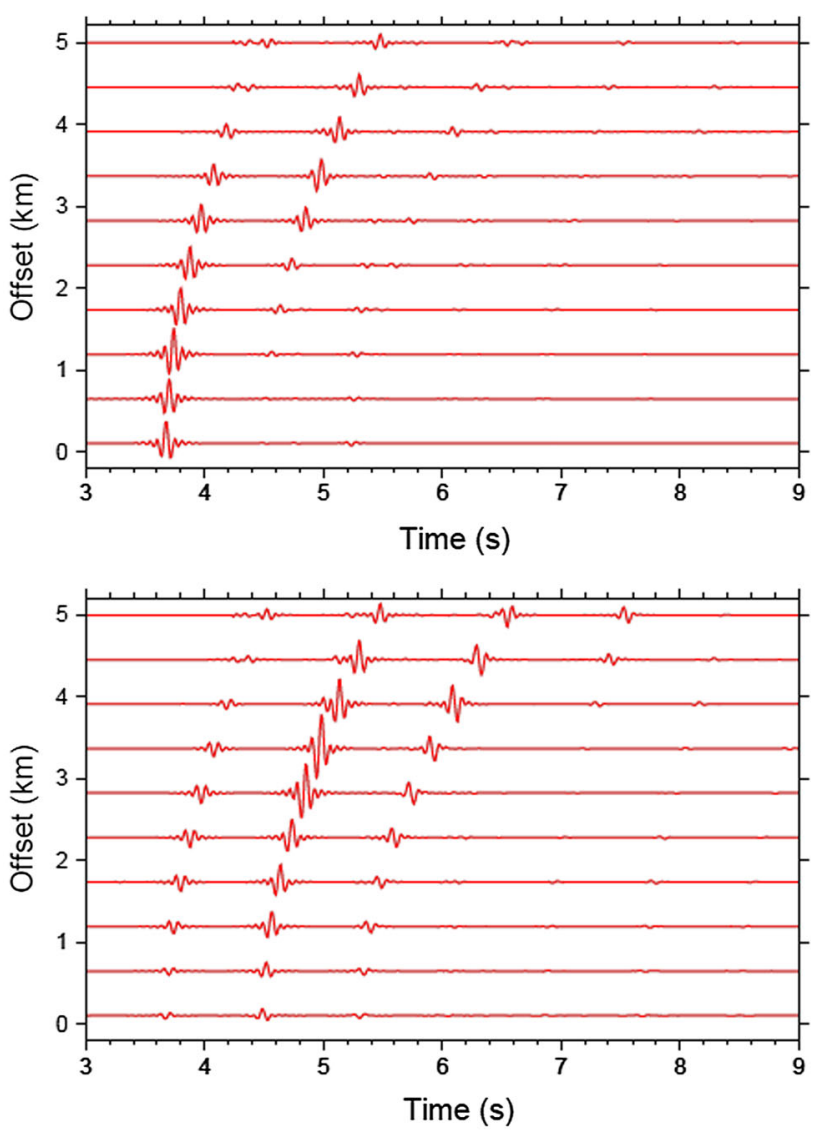

Fig. 5 Comparison of vertical (upper panel) and radial (lower panel) component waveforms (black) used for the inversion with those (red) calculated from average final models in the seven subpopulations

become "frustrate" - ensuring the search efficiency of the NGA.

\section{Effect of different observation systems}

In the previous discussion, the receivers were always arranged in a line, with the goal of achieving an along-axis profile. However, there are several ways to set the observation system based on different research purposes. This section discusses the feasibility of NGA inversion methods using a variety of observation systems. 


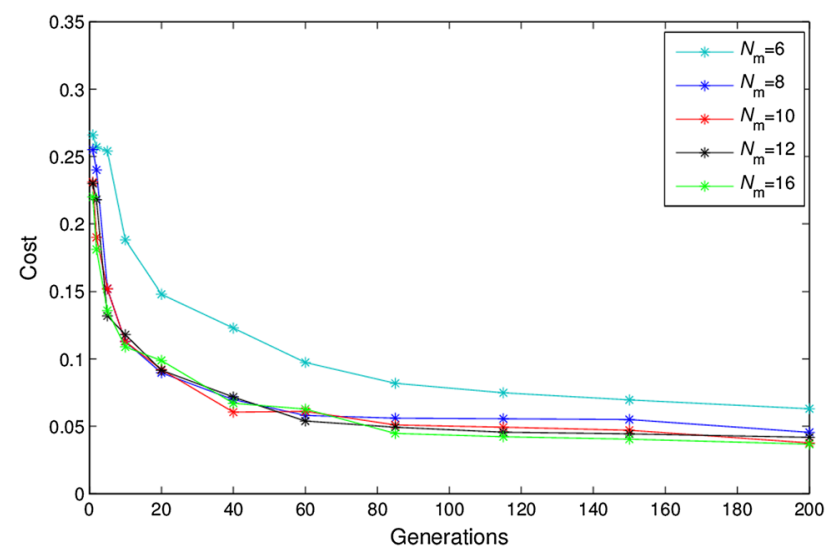

Fig. 6 Cost versus generations, for the tests described in Sect. 4.2. The results are obtained for five different $N_{\mathrm{m}}$ values

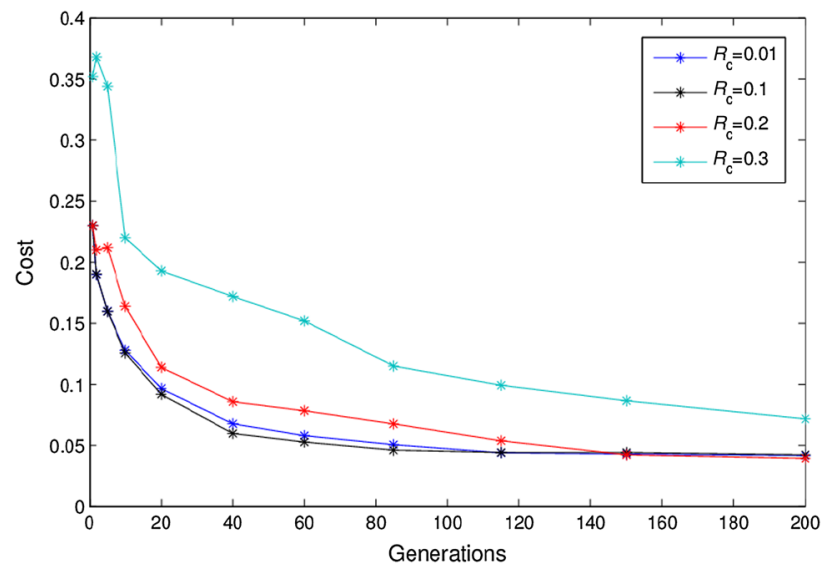

Fig. 7 Cost versus generations, for the tests described in Sect. 4.3. The results are obtained for four different $R_{\mathrm{c}}$ values

\subsection{Irregular and sparse distribution of receivers}

Four receivers are set at different distances from the source and azimuths with respect to the source as shown in Fig. 8. In some cases, it was not possible to set a sufficient number of OBS in line, due to the constraints of the situation. Furthermore, data from the irregular distribution of OBS give the average 1D structure of a wider area, while linear arrangement just focuses on the profile. Therefore, it is necessary to perform tests for such an OBS network. The results of these tests are presented in Table 3 and Figs. 9, 10 , and 11. A good fitting of the waveform is still observed.

\subsection{Single receiver}

Even though the observation system could include many accurately timed, high-gain seismometers, a single-station method still has advantages, of which economic cost is an important one. Tests were performed in order to examine whether single OBS data are sufficient to explore the local

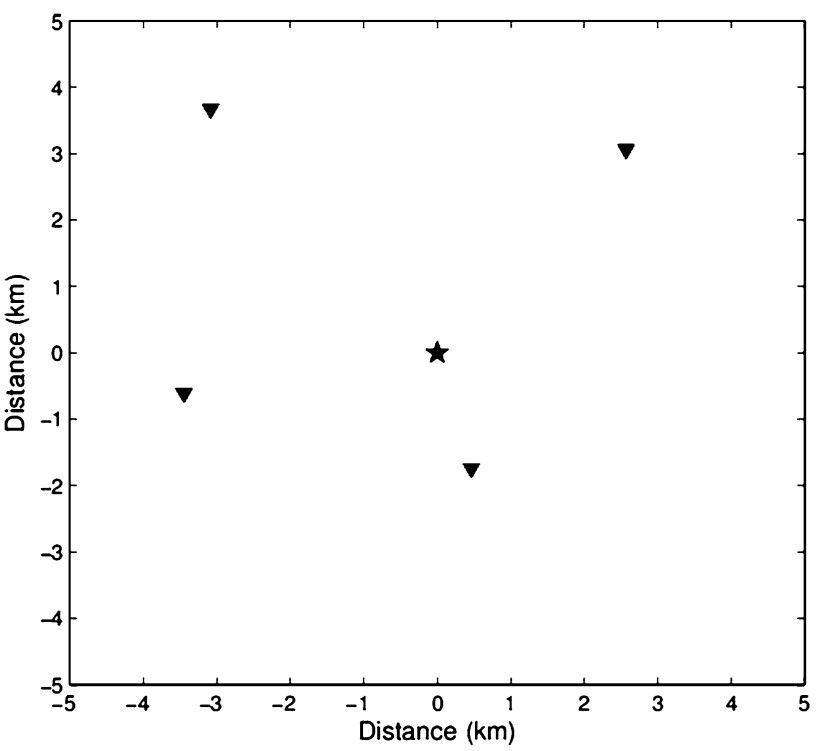

Fig. 8 The distribution of source (black star) and receivers (black triangles) in the horizontal plane

crust structure. The distance of the OBS to the source is $3.5 \mathrm{~km}$. The results of the tests are presented in Table 4 and Figs. 12, 13, and 14. The waveform fitting is sufficiently good to validate the single receiver method.

\section{Strategy to speed up convergence}

Through observation of the evolution of cost values in the previous numerical tests, it is apparent that calculating for more generations gives a final model with a lower cost value, but that this comes at the expense of significantly increased time consumption. Because significant changes rarely take place after about 100 generations, as shown by the cost-generation curves, it is proposed to use the result of the first few generations to further narrow the range of each parameter to conduct a second inversion. Generally speaking, a smaller search range leads to a better inversion result, and this can be judged by comparison of the value of the object function.

In this section, the two experiments described in Sect. 5 are revisited, with the results of the 15th generation used. The mean value and standard deviation $\sigma$ of each parameter are calculated, and used to set the upper and lower bound of a new search range equal to mean $\pm 3 \sigma$. A coefficient smaller than 3 would be more favorable, but would increase the risk that the parameter value of the real model would not be included in the search range, thus making this inversion a failure. For this reason, 3 is chosen as the coefficient, which gives a limited restriction on the range as shown in Tables 5 and 6. 
Table 3 Comparison of results from waveform inversion with the theoretical model, for the tests described in Sect. 5.1

\begin{tabular}{|c|c|c|c|}
\hline $\begin{array}{l}\text { Theoretical model } \\
\text { thickness } H(\mathrm{~km})\end{array}$ & $\begin{array}{l}\text { Inversion result thickness } \\
H \pm \sigma(\mathrm{km})\end{array}$ & $\begin{array}{l}\text { Theoretical model P-wave } \\
\text { velocity } v_{\mathrm{P}}(\mathrm{km} / \mathrm{s})\end{array}$ & $\begin{array}{l}\text { Inversion result P-wave } \\
\text { velocity } v_{\mathrm{P}} \pm \sigma(\mathrm{km} / \mathrm{s})\end{array}$ \\
\hline 1.8 & $1.805 \pm 0.015$ & 2.3 & $2.306 \pm 0.018$ \\
\hline 3.0 & $3.189 \pm 0.418$ & 5.5 & $5.518 \pm 0.076$ \\
\hline 2.5 & $2.505 \pm 0.386$ & 6.7 & $6.570 \pm 0.220$ \\
\hline \multirow[t]{2}{*}{4.0} & $4.034 \pm 0.772$ & 7.1 & $7.065 \pm 0.216$ \\
\hline & & 8.1 & $7.967 \pm 0.227$ \\
\hline
\end{tabular}

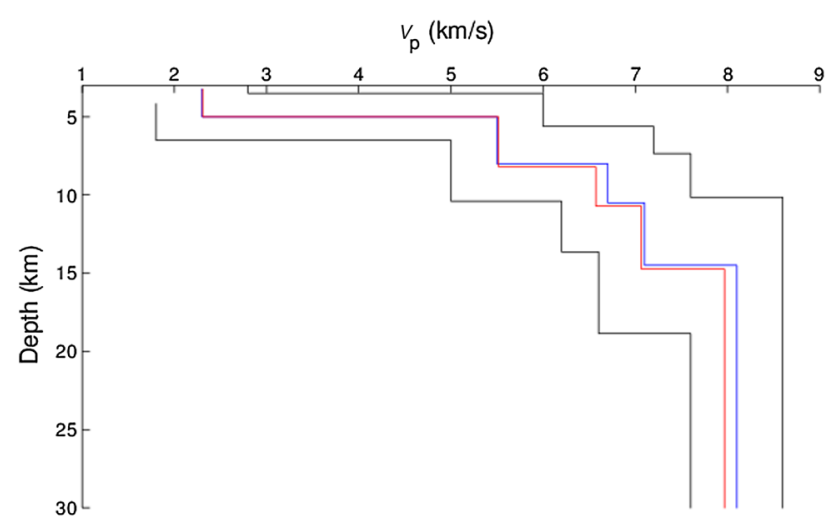

Fig. 9 Comparison of the average model (red line) from seven NGA inversions with the true models (blue line). The preset ranges for velocity and depth in which the model parameters are allowed to change in the inversion are shown by black lines, for the tests described in Sect. 5.1

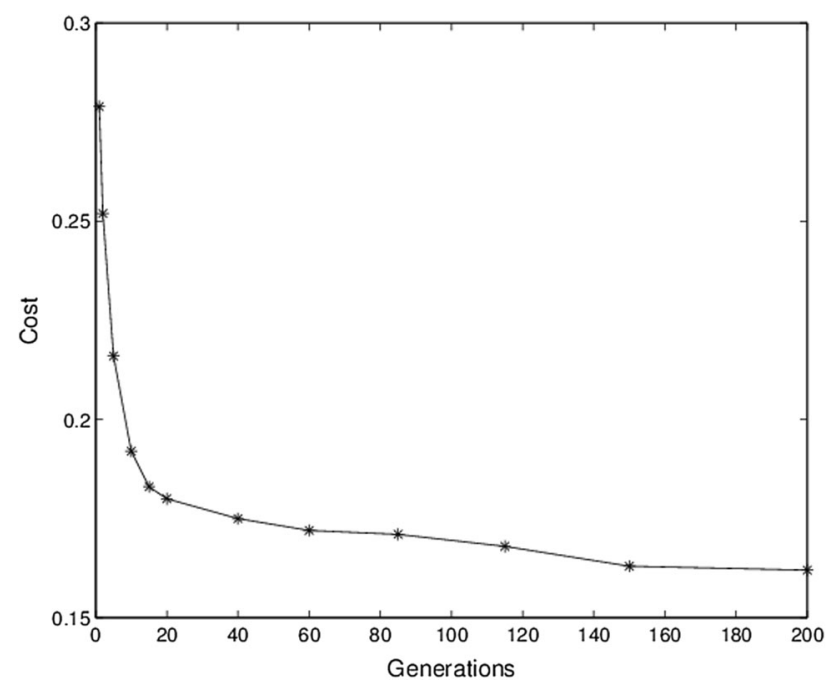

Fig. 10 Cost versus generations. This result is from the situation in which OBS are located irregularly and sparsely, for the tests described in Sect. 5.1

From Tables 5 and 6 , it can be seen that the range restriction greatly limits the range of the top two layers, especially the first layer, and that improvements on the upper layers have significant consequences. Because each
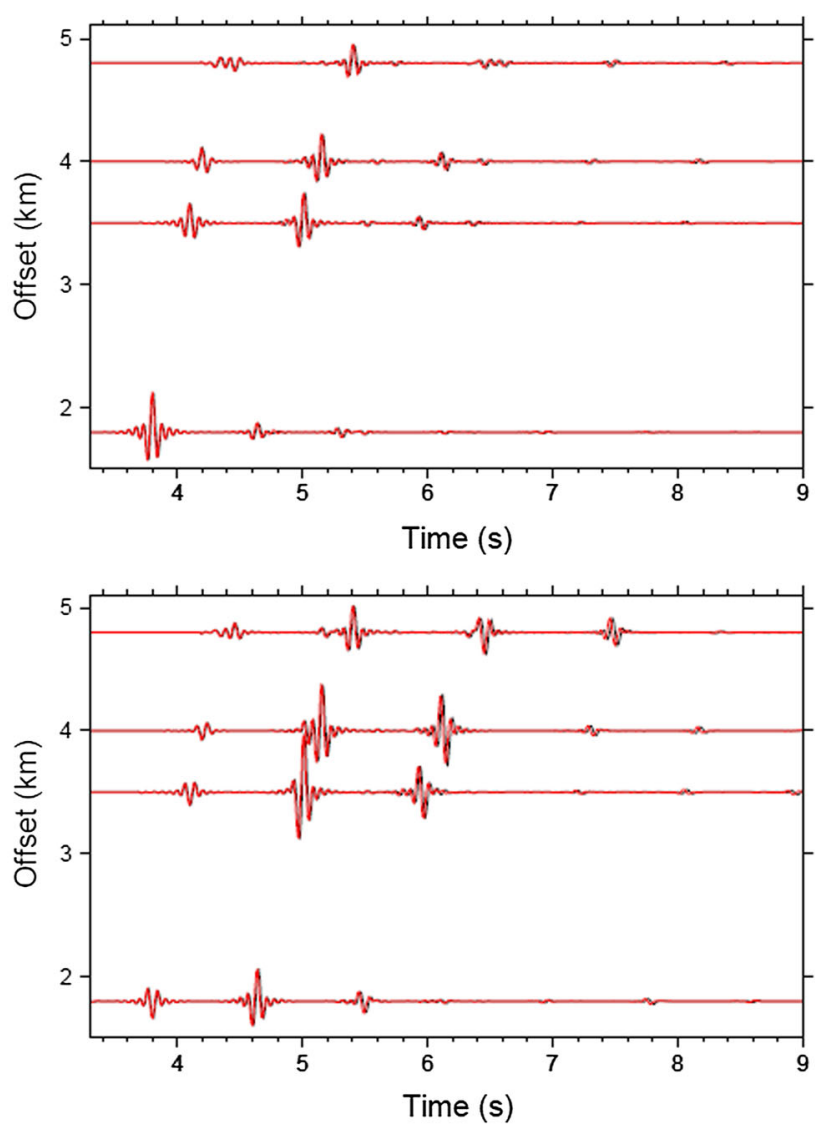

Fig. 11 Comparison of vertical (upper panel) and radial (lower panel) component waveforms (black) used for the inversion with those (red) calculated from average final models in the seven inversions, for the tests described in Sect. 5.1

reflection wave phase travels through upper layers, if the velocity and thickness values deviate away from the actual ones too much, then it will be difficult for all of the seismic phases to arrive at the correct time, which increases the difficulty of waveform fitting. Therefore, better estimation of the upper layers is crucial, and the range restriction strategy contributes to a reduction of its uncertainty.

The essence of this strategy is to reduce the searching range of model parameters from the first inversion within a 
Table 4 Comparison of results for the tests described in Sect. 5.2, with a source receiver offset of $3.5 \mathrm{~km}$

\begin{tabular}{|c|c|c|c|}
\hline $\begin{array}{l}\text { Theoretical model } \\
\text { thickness } H(\mathrm{~km})\end{array}$ & $\begin{array}{l}\text { Inversion result thickness } \\
H \pm \sigma(\mathrm{km})\end{array}$ & $\begin{array}{l}\text { Theoretical model P-wave } \\
\text { velocity } v_{\mathrm{P}}(\mathrm{km} / \mathrm{s})\end{array}$ & $\begin{array}{l}\text { Inversion result P-wave } \\
\text { velocity } v_{\mathrm{P}} \pm \sigma(\mathrm{km} / \mathrm{s})\end{array}$ \\
\hline 1.8 & $1.796 \pm 0.023$ & 2.3 & $2.296 \pm 0.024$ \\
\hline 3.0 & $2.924 \pm 0.277$ & 5.5 & $5.488 \pm 0.026$ \\
\hline 2.5 & $2.499 \pm 0.555$ & 6.7 & $6.575 \pm 0.216$ \\
\hline \multirow[t]{2}{*}{4.0} & $4.299 \pm 0.612$ & 7.1 & $7.006 \pm 0.293$ \\
\hline & & 8.1 & $8.164 \pm 0.229$ \\
\hline
\end{tabular}

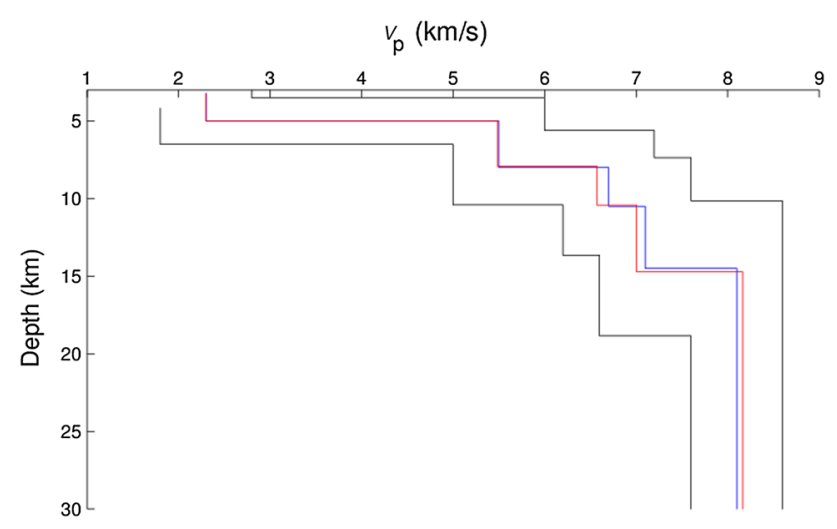

Fig. 12 Comparison of the average model (red line) from seven NGA inversions with the true models (blue line). The preset ranges for velocity and depth, in which the model parameters are allowed to change in the inversion, are shown by black lines, for the tests described in Sect. 5.2

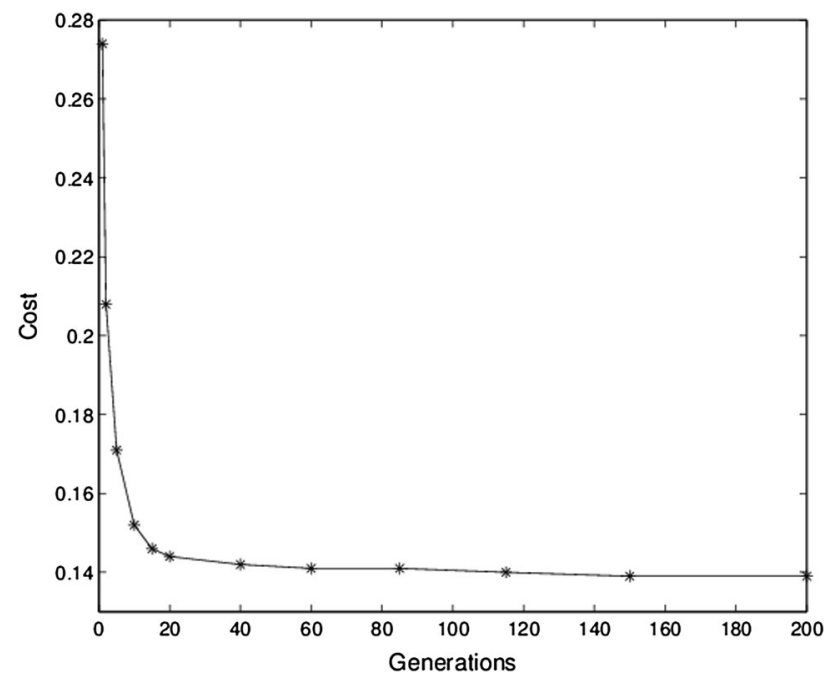

Fig. 13 Cost versus generations. This result is from the situation in which the OBS is located $3.5 \mathrm{~km}$ away, for the tests described in Sect. 5.2

few generations, and then to carry out a new, second, inversion with the narrowed range. It is seen that convergence on the global minimum is more likely after several
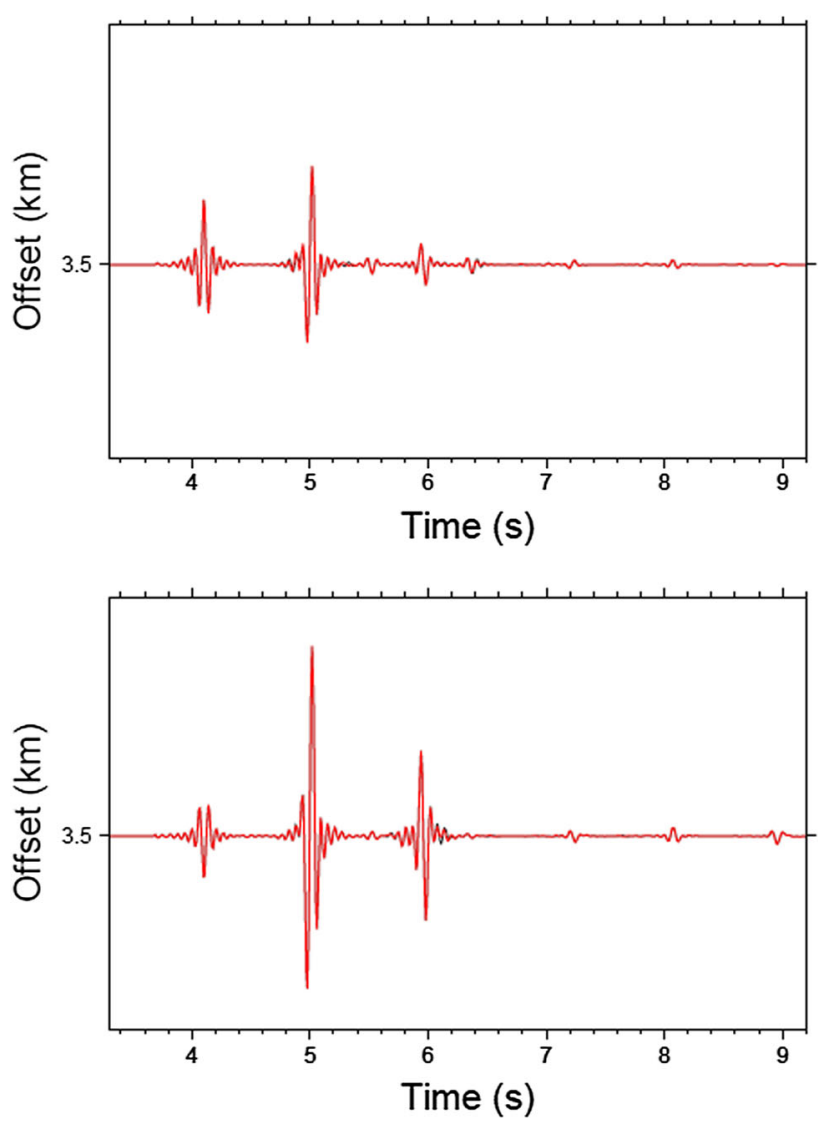

Fig. 14 Comparison of vertical (upper panel) and radial (lower panel) component waveforms (black) used for the inversion with those (red) calculated from average final models in the seven subpopulations, for the tests described in Sect. 5.2

generations in the second inversion. By applying this strategy, it takes less than 50 generations to obtain a result that has a similar cost value as was found from the ordinary inversion as shown in Fig. 15. A time saving of almost $80 \%$ is made in this way, demonstrating that the computational efficiency is greatly enhanced.

This strategy utilizes a simple "mean $\pm k \sigma$ " approach, but there remains a question of optimal selection of the constant $k$. This work set $k$ equal to 3 , and the results show 
Table 5 Comparison of the search range, before and after restriction, for the tests described in Sect. 5.1

\begin{tabular}{lll}
\hline Model thickness $H_{0}(\mathrm{~km})$ & Search range before restriction & Search range after restriction \\
\hline 1.8 & $1.26-2.34$ & $1.72-1.91$ \\
3.0 & $2.10-3.90$ & $2.35-3.50$ \\
2.5 & $1.75-3.25$ & $1.91-3.25$ \\
4.0 & $2.80-5.20$ & $2.80-5.20$ \\
\hline Model $V_{\mathrm{P}}$ & Search range before restriction & Search range after restriction \\
$v_{\mathrm{P} 0}(\mathrm{~km} / \mathrm{s})$ & & \\
\hline 2.3 & $1.80-2.80$ & $2.21-2.43$ \\
5.5 & $5.00-6.00$ & $5.07-5.91$ \\
6.7 & $6.20-7.20$ & $6.20-7.20$ \\
7.1 & $6.60-7.60$ & $6.60-7.60$ \\
8.1 & $7.60-8.60$ & $7.60-8.60$ \\
\hline
\end{tabular}

\begin{tabular}{lll}
\hline Model thickness $H_{0}(\mathrm{~km})$ & Search range before restriction & Search range after restriction \\
\hline 1.8 & $1.26-2.34$ & $1.66-1.89$ \\
3.0 & $2.10-3.90$ & $2.10-3.90$ \\
2.5 & $1.75-3.25$ & $1.75-3.25$ \\
4.0 & $2.80-5.20$ & $2.80-5.20$ \\
\hline Model $V_{\mathrm{P}}$ & Search range before restriction & Search range after restriction \\
$\nu_{\mathrm{P} 0}(\mathrm{~km} / \mathrm{s})$ & & \\
\hline 2.3 & $1.80-2.80$ & $2.16-2.39$ \\
5.5 & $5.00-6.00$ & $5.02-5.96$ \\
6.7 & $6.20-7.20$ & $6.23-7.14$ \\
7.1 & $6.60-7.60$ & $6.60-7.60$ \\
8.1 & $7.60-8.60$ & $7.60-8.60$ \\
\hline
\end{tabular}

Table 6 Comparison of the search ranges before and after restriction, for the tests described in Sect. 5.2 (a)

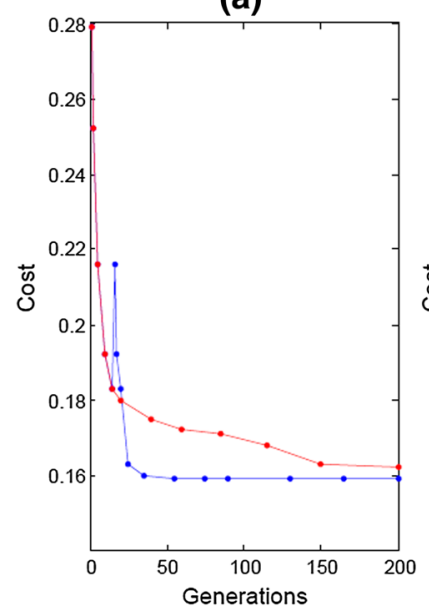

(b)

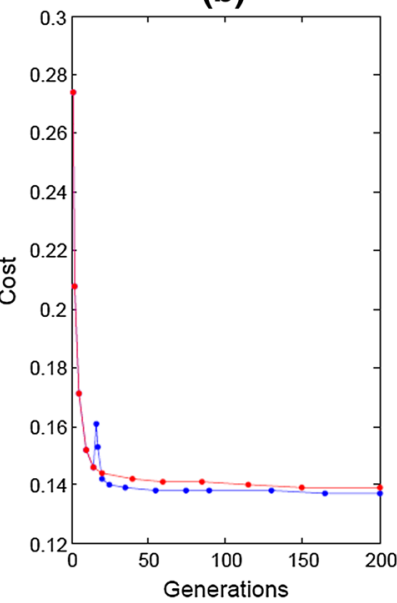

Fig. 15 Comparison of cost-generation curves of prerange-restriction test (red) with those with the range restriction strategy applied (blue): a the irregular and sparse OBS distribution described in Sect. 5.1 and b the single OBS test described in Sect. 5.2. The sharp rise is caused by the reshuffling of all the parameter values from the new, restricted ranges to determine the initial model for the second inversion

that 3 is a suitable value, but it is not proven to be the ideal value. It may be difficult to prove the existence of an optimal $k$ value, and so the value should be based on practical experience of real cases.

\section{Discussion and conclusions}

This work attempted to invert the waveform recorded by OBS using a synthetic model, for the purpose of studying the structure of the oceanic crust. Tests were carried out on the parameters of a niching genetic algorithm in order to determine appropriate values. Parameter values of $N_{\mathrm{m}}$ equal to 10 and of $R_{\mathrm{c}}$ between 0.1 and 0.2 were found to be favorable. Different observation systems, irregular distribution and single station, were studied, and results showed that both offered quite good waveform fitting. A strategy was proposed to accelerate the convergence rate and its effectiveness was verified. In conclusion, using OBS data for waveform inversion is effective in the study of a 
regional oceanic crust structure that can be approximated by a layered model.

Limitations as well as advantages were found. Most significantly, this method is confined to a circular range of several kilometers, where the direct wave in water does not overlap with the useful reflection signals. By setting the thickness of the water layer to $3.2 \mathrm{~km}$, a circular area of $5 \mathrm{~km}$ radius is available. This radius will be smaller if the depth of the sea level is shallower, as the direct wave will suppress the reflected wave at a close distance. Measures should be taken in order to study larger areas, and in particular, an effective method is required to ignore the direct wave while not adding artificial noise to the reflection signals. In addition, this study used a Ricker wavelet to approximate the air-gun source signal, but the real seismic source is much more complicated. Many researchers have discussed improved approximation of the real bubble behavior (e.g., Johnson 1994; SchulzeGattermann 1972), but this was not included in this study. This study did not consider the influence of different source time functions, but if an accurate expression of air-gun source time function is calculated, then this will offer a better simulation of the real situation.

Acknowledgments This research was supported by the National Natural Science Foundation grant No. 41174034 and the Major State Basic Research Development Program of China (973 Program).

Open Access This article is distributed under the terms of the Creative Commons Attribution 4.0 International License (http://crea tivecommons.org/licenses/by/4.0/), which permits unrestricted use, distribution, and reproduction in any medium, provided you give appropriate credit to the original author(s) and the source, provide a link to the Creative Commons license, and indicate if changes were made.

\section{References}

Abdelwahed MF, Zhao D (2014) Genetic waveform modeling for the crustal structure in Northeast Japan. J Asian Earth Sci 89:66-75

Arnulf AF, Harding AJ, Singh SC, Kent GM, Crawford WC (2014) Nature of upper crust beneath the Lucky Strike volcano using elastic full inversion of streamer data. Geophys J Int 196:1471-1491

Borisov D, Singh SC (2015) Three-dimensional elastic full waveform inversion in a marine environment using multicomponent oceanbottom cables: a synthetic study. Geophys J Int 201:1215-1234. doi:10.1093/gji/ggv048

Cara M, Lévêque JJ (1987) Waveform inversion using secondary observables. Geophys Res Lett 14(10):1046-1049

Chang SJ, Baag CE (2006) Crustal structure in southern Korea from joint analysis of regional broadband waveforms and travel times. Bull Seismol Soc Am 96(3):856-870

Das T, Nolet G (1998) Crustal thickness map of the western United States by partitioned waveform inversion. J Geophys Res 103(B12):30021-30038

Debayle E, Lévêque JJ (1997) Upper mantle heterogeneities in the Indian Ocean from waveform inversion. Geophys Res Lett 24(3):245-248
Fuchs K, Müller G (1971) Computation of synthetic seismograms with the reflectivity method and comparison with observations. Geophys J Int 23(4):417-433

Igel H, Djikpéssé H, Tarantola A (1996) Waveform inversion of marine reflection seismograms for P impedance and Poisson's ratio. Geophys J Int 124(2):363-371

Jian H, Singh SC, Chen YJ, Li J (2014) Imaging of lower-crustal magma chambers at an ultraslow spreading ridge segment using elastic waveform inversion of a sparse OBS dataset. In: AGU Fall Meeting Abstracts, vol 1. p 4752

Johnson DT (1994) Understanding air-gun bubble behavior. Geophysics 59(11):1729-1734

Koper KD, Wysession ME, Wiens DA (1999) Multimodal function optimization with a niching genetic algorithm: A seismological example. Bull Seismol Soc Am 89(4):978-988

JF Lawrence, Shearer PM (2006) Constraining seismic velocity and density for the mantle transition zone with reflected and transmitted waveforms. Geochemistry, Geophysics, Geosystems. doi: 10.1029/2006GC001339

Li C, Lei J (2014a) Numerical tests for effects of various parameters in niching genetic algorithm applied to regional waveform inversion. Earthq Sci 27(5):541-551. doi:10.1007/s11589-0140095-7

Li C, Lei J (2014b) Crustal velocity structure under southwestern Yunnan from regional waveform inversion. Chin Sci Bull 59:3398-3415. doi: 10.1360/N972014-00407Li (in Chinese with English abstract)

Li H, Michelini A, Zhu L (2007) Crustal velocity structure in Italy from analysis of regional seismic waveforms. Bull Seismol Soc Am 97(6):2024-2039

Li SH, Wang YB, Liang ZB, He SL, Zeng WH (2012) Crustal structure in southeastern Gansu from regional seismic waveform inversion. Chin J Geophys 55(4):1186-1197. (in Chinese with English abstract)

Li J, Jian H, Chen YJ, Singh SC, Ruan A, Qiu X, Zhao M, Wang X, Niu X, Ni J, Zhang J (2015) Seismic observation of an extremely magmatic accretion at the ultraslow spreading Southwest Indian Ridge. Geophys Res Lett 42(8):2656-2663

Mahfoud SW (1995) Niching methods for genetic algorithms. Ph.D. dissertation, University of Illinois at Urbana-Champagne

Maurice R, Stacey D, Wiens DA, Koper KD, Vera E (2003) Crustal and upper mantle structure of southernmost South America inferred from regional waveform inversion. J Geophys Res. doi: $10.1029 / 2002 J B 001828$

Mendes M, Beydoun W, Planchon JM, Tarantola A (1990) Seismic identification of a karstified reservoir in the Adriatic Sea. Geophysics 55(12):1639-1644

Operto S, Virieux J, Dessa JX, Pascal G (2006) Crustal seismic imaging from multifold ocean bottom seismometer data by frequency domain full waveform tomography: application to the eastern Nankai trough. J Geophys Res 111:B09306. doi:10.1029/ 2005JB003835

Pratt RG (1999) Seismic waveform inversion in the frequency domain, Part 1: theory and verification in a physical scale model. Geophysics 64(3):888-901

Rao PP, Rajput S, Ashalatha B, Shankar U, Sain K, Naidu MS, Rriveni V, Thakur NK (2012) Lithospheric structure model of Central Indian Ocean Basin using ocean bottom seismometer data. J Earth Sci Eng 2:344-359

Schulze-Gattermann R (1972) Physical aspects of the "airpulser" as a seismic energy source. Geophys Prospect 20(1):155-192

Seher T, Crawford WC, Singh SC, Cannat M, Combier V, Dusunur D (2010) Crustal velocity structure of the Lucky Strike segment of the Mid-Atlantic Ridge at $37 \mathrm{~N}$ from seismic refraction measurements. J Geophys Res. doi:10.1029/2009JB006650 
Sen MK, Stoffa PL (2013) Global optimization methods in geophysical inversion. Cambridge University Press, Cambridge

Sherrington HF, Zandt G, Frederiksen A (2004) Crustal fabric in the Tibetan Plateau based on waveform inversions for seismic anisotropy parameters. J Geophys Res. doi:10.1029/ 2002JB002345

Shibutani T, Sambridge M, Kennett B (1996) Genetic algorithm inversion for receiver functions with application to crust and uppermost mantle structure beneath eastern Australia. Geophys Res Lett 23(14):1829-1832

Takahashi N, Kodaira S, Tsuru T, Park JO, Kaneda Y, Suyehiro K, Kinoshita H, Abe S, Nishino M, Hino R (2004) Seismic structure and seismogenesis off Sanriku region, northeastern Japan. Geophys J Int 159(1):129-145
Virieux J, Operto S (2009) An overview of full-waveform inversion in exploration geophysics. Geophysics 74(6):WCC1-WCC26

Zhao M, Qiu X, Xia S, Xu H, Wang P, Wang TK, Lee CS, Xia K (2010) Seismic structure in the northeastern South China Sea: $\mathrm{S}$-wave velocity and $v_{\mathrm{P}} / v_{\mathrm{S}}$ ratios derived from three-component OBS data. Tectonophysics 480(1):183-197

Zheng T, Chen L, Zhao L, Xu W, Zhu R (2006) Crust-mantle structure difference across the gravity gradient zone in North China Craton: seismic image of the thinned continental crust. Phys Earth Planet Inter 159(1):43-58

Zhu L, Mitchell BJ, Akyol N, Cemen I, Kekovali K (2006) Crustal thickness variations in the Aegean region and implications for the extension of continental crust. J Geophys Res 111:B01301. doi:10.1029/2005JB003770 